University of Arkansas, Fayetteville

ScholarWorks@UARK

Education Reform Faculty and Graduate

Students Publications

$10-2020$

\title{
Teachers' Willingness to Pay for Retirement Benefits: A National Stated Preferences Experiment
}

Dillon Fuchsman

Saint Louis University, dillon.fuchsman@slu.edu

Josh B. McGee

University of Arkansas, Fayetteville, jbm04@uark.edu

Gema Zamarro

University of Arkansas, Fayetteville, gzamarro@uark.edu

Follow this and additional works at: https://scholarworks.uark.edu/edrepub

Part of the Educational Assessment, Evaluation, and Research Commons, Educational Leadership Commons, and the Other Educational Administration and Supervision Commons

\section{Citation}

Fuchsman, D., McGee, J. B., \& Zamarro, G. (2020). Teachers' Willingness to Pay for Retirement Benefits: A National Stated Preferences Experiment. Education Reform Faculty and Graduate Students Publications. Retrieved from https://scholarworks.uark.edu/edrepub/118

This Article is brought to you for free and open access by the Education Reform at ScholarWorks@UARK. It has been accepted for inclusion in Education Reform Faculty and Graduate Students Publications by an authorized administrator of ScholarWorks@UARK. For more information, please contact scholar@uark.edu. 


\title{
Teachers' Willingness to Pay for Retirement Benefits: A National Stated PREFERENCES EXPERIMENT
}

\author{
Dillon Fuchsman* \\ dillon.fuchsman@slu.edu
}

\author{
Josh B. McGee ${ }^{\dagger}$ \\ joshmcgee@uark.edu
}

\author{
Gema Zamarro ${ }^{\dagger}$ \\ gzamarro@uark.edu
}

DRAFT: October 2020

\begin{abstract}
Many states have recently made or are considering changes to their teacher retirement systems. However, little is known about how teachers value various elements of their retirement benefits versus other aspects of their jobs and compensation. To help alleviate this gap, we use a discrete choice stated preferences experiment embedded in a nationally representative survey of teachers to estimate their willingness-to-pay for various retirement plan characteristics and other non-salary job components. We find that teachers would be indifferent between a traditional pension and alternative retirement plan designs if the alternatives were paired with 2 to 3 percent salary increases. Our results indicate that experience is a significant mediator of retirement plan preferences. While more experienced teachers are willing to pay more to keep their traditional pension plans, inexperienced teachers do not have strong preferences around retirement plan type. However, teachers' willingness-to-pay for traditional pension plans is less than their willingness-to-pay for many other elements of their compensation, including the value of retirement benefits, retirement age, salary growth, healthcare coverage, and Social Security enrollment.
\end{abstract}

JEL CODES: I20, J33

KEYWORDS: teacher pensions, stated preferences, discrete choice experiment

ACKNOWLedgements: We thank the Walton Family Foundation and the Equable Institute for financial support. We thank Heidi Erickson for her help on earlier versions of this work. We thank Robert Costrell and conference participants at the $45^{\text {th }}$ Annual AEFP Conference for their comments.

\footnotetext{
* Corresponding author. Sinquefield Center for Applied Economic Research, Saint Louis University, Saint Louis, MO 63108

${ }^{\dagger}$ Department of Education Reform, University of Arkansas, Fayetteville, AR 72701.
} 


\section{INTRODUCTION}

Retirement benefits are an important part of teachers' compensation packages and millions of retired teachers rely on government-sponsored pension plans for their livelihood. Unfortunately, states and school districts have not set enough money aside to fully cover the benefits teachers have already earned. Teachers' pensions in the United States are only 72 percent funded on average and have total unfunded liabilities exceeding $\$ 600$ billion, a sum that is likely to increase in the coming years as plans adopt more conservative assumptions and grapple with a challenging investment environment (McGee, 2019; Novy-Marx \& Rauh, 2011; Public Plans Data, 2020). As a result of these funding shortfalls, annual per-pupil teacher retirement costs have nearly tripled since 2004 , rising from $\$ 547$ to $\$ 1,520$, and now account for 11 percent of the total per-pupil education expenditures (Costrell, 2020). Soaring pension costs crowd out other government expenditures, leaving less money to pay today's teachers, affecting both take-home salary and benefits (Kim et al., 2020; McGee, 2016; Nation, 2018).

In recent years, many states have changed teachers' retirement benefits to stem rising costs. Most changes to teachers' retirement plans maintain the traditional final-average-salary defined benefit (FAS) design but alter parameters like retirement age, how much teachers earn for each year of work, and how much teachers contribute to the plan. Several states have considered but few have adopted (e.g., Kansas, Washington, etc.) alternative pension plan designs like defined contribution (DC), cash balance (CB), and hybrid plans that combine elements of two or more models. ${ }^{1}$ Benefit changes disproportionately affect new teachers, substantially reducing the value of retirement benefits for the next generation of educators.

\footnotetext{
${ }^{1}$ The various plan designs are described more fully in section II.
} 
These changes to teachers' retirement plans have the potential to substantially alter teacher labor markets (e.g., Brown, 2013; Costrell \& McGee, 2010). Advocates for generous traditional FAS pensions contend that benefit reductions and/or plan design changes will harm states' ability to recruit and retain talented teachers (Boivie, 2011, 2017). They argue that teachers prefer FAS plans to alternative plans and that traditional pensions are effective workforce management tools that incentivize retention and orderly turnover at known retirement ages. However, when offered alternative plans, a substantial percentage of teachers choose the alternatives, and the evidence on traditional pensions' effectiveness as a workforce management tool is limited and mixed at best (Chingos \& West, 2015; Goldhaber et al., 2017).

In the coming years, states and school districts will face increased budgetary pressure resulting from the COVID-19 recession. Tax revenue is expected to decline sharply in many states (Dadayan, 2020), and pension costs are likely to rise because the virus's economic disruption will make it difficult for pension plans to meet their expected investment return targets. Because of these factors, pension reform will almost certainly continue to be a topic of conversation in state legislatures.

To inform the tradeoffs that policymakers face, we designed an experiment to quantify how teachers' value various job attributes, including retirement plan design and characteristics. We administered a survey to a nationally representative sample of teachers from the RAND Corporation's American Teacher Panel. We embedded a discrete choice stated preferences experiment in this survey. The design of our experiment closely follows work by Maestas et al. (2018) and Mas and Pallais (2017). We repeatedly asked respondents to choose between two jobs which are the same in every way except they have different randomly assigned salaries and vary on one non-salary characteristic (e.g., retirement plan type, retirement age, Social Security 
enrollment, etc.). We use respondents' choices to estimate their willingness-to-pay for specific job characteristics. We explore potential heterogeneity in preferences based on respondents' teaching experience, cognitive ability, conscientiousness, financial literacy, and risk tolerance. ${ }^{2}$

Our main results indicate that teachers would be accept being enrolled in alternative retirement plan designs if they are compensated with modest salary increases, marginally larger expected retirement benefits, or slightly earlier retirement eligibility. We also find that experience substantially mediates willingness-to-pay for alternative retirement plans. While the most experienced teachers have a relatively strong preference for FAS plans, early-career teachers are indifferent between FAS plans and either DC or CB plans. Respondents also placed a significantly higher value on enrolling in Social Security than they did on maintaining participation in FAS plans. Additionally, we find that teachers with higher cognitive ability, higher financial literacy, and lower levels of risk tolerance are willing to pay more for FAS plans.

These findings make three key contributions to the literature. First, our nationally representative stated preferences experiment allows us to quantify teachers' preferences for various job characteristics, including retirement plan design, in dollar terms. While others have asked teachers about their preferences around retirement plans, we are not aware of any prior research that estimates willingness to pay using a nationally representative sample (DeArmond \& Goldhaber, 2010; Johnston, 2020). Second, we are the first to estimate teachers' preferences around CB plans, which have been considered by several states and was recently adopted for new hires in Kansas (Costrell, 2019). Finally, we estimate preferences for a variety of job conditions across a number of potential values. While others infer preferences for deferred versus current compensation given a real-world policy change (Biasi, 2019; Fitzpatrick, 2015; Goldhaber \&

\footnotetext{
${ }^{2}$ Both cognitive ability and conscientiousness serve as proxies for teacher quality (Cheng \& Zamarro, 2018; Hanushek et al., 2018).
} 
Holden, 2020), their estimates are limited by the specifics of the choice offered to workers. Our design is more flexible, allowing us to compare a wider variety of retirement plan features and other job characteristice.

The rest of this paper is organized into six sections. The next section provides background on teacher pensions and teachers' preferences for retirement. Section III characterizes our survey and RAND's American Teacher Panel. In section IV, we develop our stated preferences experiment. The following section describes our econometric approach to estimating teachers' willingness-to-pay for job conditions. The results of our stated preferences experiment are in section VI. We conclude with policy implications in section VII.

\section{BACKGROUND}

\section{Teacher Retirement Plan Overview}

The vast majority of teachers participate in FAS retirement plans that base benefits on years of service and end-of-career salary (U.S. Bureau of Labor Statistics, 2019). ${ }^{3}$ As noted above, these plans have proven challenging to manage in a fiscally sustainable way, leading to rising costs and multiple rounds of benefit changes for teachers. However, they may still be valuable if they offer positive labor market effects. This section describes the specifics of FAS plans as well as the alternative plan designs we model in our stated preferences experiment.

Under FAS systems, teachers are eligible to receive a set annual benefit for the remainder of their life once they reach the plan's retirement eligibility thresholds, which are generally defined in terms of age and years of service. A teacher's annual retirement benefit is determined by first multiplying their years of service in the system at retirement by the plan's benefit multiplier to get their replacement rate (i.e., the percentage of their pre-retirement salary that their benefit will

\footnotetext{
${ }^{3}$ Teachers' end-of-career salaries, or final average salaries, are typically the teachers' average salary over the last 3 to 5 years of teachers' careers.
} 
replace). To calculate a teacher's annual benefit, their replacement rate is multiplied by their average salary over their last few years in the classroom. The key features of FAS plans that we model in our experiment are the retirement eligibility thresholds (i.e., retirement age) and the replacement rate.

Benefits under FAS plans are typically backloaded, meaning teachers earn relatively meager benefits through much of their careers and then the value of those benefits increases dramatically as they approach retirement eligibility. As a result of backloading, pension accruals make up a large share of total compensation for highly-experienced teachers (McGee \& Winters, 2017). While FAS plans work well for teachers who spend a full career in a single retirement system (e.g. state), these plans often leave teachers in a retirement insecure position for much of their careers (Aldeman \& Johnson, 2015). These plans also create strong incentives to work until retirement eligibility and then to leave the classroom. These incentives are blunt and are not always aligned with schools' labor market needs or individual teachers' desire to leave before or work after retirement eligibility (Costrell \& Podgursky, 2009).

DC and CB plans are often considered as alternatives to FAS plans. DC plans, such as private sector $401(\mathrm{k})$ plans, base benefits on how much money has accrued in individual accounts from employer and employee contributions and investment returns. CB plans are a type of defined benefit plan where benefits accrue like a DC plan but that offers a minimum guaranteed benefit.

Both alternative plan types can be designed to be cost equivalent to any FAS plan. The primary differences between the various plan types are 1) how investment risk is distributed and 2) how teachers earn benefits across their careers. Because they tie benefits more closely to investment returns, the alternative plans generally reduce government cost uncertainty (Costrell, 2019; Costrell \& Podgursky, 2009). On the other hand, both alternatives place more direct 
investment risk on participating teachers. FAS plans have similar investment risks, but the associated costs are only born by teachers indirectly through crowd out effects on salary and job conditions and reduced retirement benefits for young and new teachers.

The backloaded nature of FAS plans is also risky for teachers because, if they do not work a full career under a single system, they are often left with meager savings, placing them in a retirement insecure position. Both DC and CB plans offer more even benefit accrual, albeit with somewhat lower maximum benefit levels for full-career teachers. Theoretical evidence suggests that teachers, especially early-career teachers, may prefer earning benefits more evenly across their careers to limit the risk of leaving the profession early with little to show for it (McGee \& Winters, 2018).

\section{Preferences and Willingness-to-Pay for Retirement}

Although we are not the first to estimate preferences using survey methodology (e.g., DeArmond \& Goldhaber, 2010; Horng, 2009; Johnson et al., 2012; Johnston, 2020; Ladd, 2011; Viano et al., 2019), the literature on teachers' preferences around retirement benefits is quite limited. We only identified six studies and only four of these studies were related to preferences around differing retirement plan types. Two of these studies observed teachers' behavior to evaluate their preferences for retirement and found that teachers place a higher value on their current compensation than future compensation through retirement benefits (Biasi, 2019; Fitzpatrick, 2015).

Two additional studies evaluate revealed preferences for retirement plan types in Washington State and Florida (Chingos \& West, 2015; Goldhaber \& Grout, 2016). Both states allow teachers to choose to enroll in either a FAS plan or a hybrid FAS/DC plan for Washington teachers or a DC plan for Florida teachers. The default retirement plan in Washington was the FAS 
prior to 2007 when the default changed to the hybrid DB/DC plan. The majority of teachers enrolled in the hybrid plan. Younger teachers in Washington were more likely to choose the hybrid plan than the FAS plan (Goldhaber \& Grout, 2016).

The default retirement plan in Florida was the FAS plan until 2018 and most teachers enrolled in it. Older teachers in Florida were more likely to opt into the DC plan (Chingos \& West, 2015). The majority of newly hired government employees, which would include teachers, enrolled in the DC plan when it became the default in 2018 (State Board of Administration of Florida, 2020). Higher-quality teachers were more likely to enroll in alternative retirement plans (Chingos \& West, 2015; Goldhaber \& Grout, 2016).

Using a survey in Washington State, DeArmond and Goldhaber (2010) find that teachers prefer DC plans to FAS plans and that this preference was larger for teachers with less than 15 years of experience. Their survey question specifies that traditional pensions are DB plans and provide guaranteed benefits, while DC plans are similar to 401(k) or 403(b) plans and are more portable. Washington State uses a traditional FAS plan as well as a hybrid FAS/DC plan. It is reasonable to expect that early-career teachers may have a preference for the portability that DC plans afford. However, the preference for DC plans may be due to the fact that the state already has a DC component in its existing retirement plan, which allows teachers to be more familiar with how DC plans operate for teachers compared to traditional FAS plans. Thus, it is unclear how applicable DeArmond and Goldhaber's results are to other states.

The only other survey work that estimates teachers' preferences for retirement and relates to this paper is Johnston (2020). Johnston estimates teachers' stated preferences and willingnessto-pay in a single school district outside Houston, TX, using a similar discrete choice experiment to this paper. Teachers in the school district choose between two hypothetical job offers where 
several job conditions randomly vary. Johnston's job conditions include salary, salary growth, retirement plan type, replacement rate, health insurance, and class size among a variety of other conditions. He finds that teachers are willing to pay for higher replacement rates, DC plans, lower health insurance premiums, and smaller class sizes. Willingness-to-pay estimates for this Houstonarea school district indicate that teachers would equate switching to a DC plan from a DB plan and a $\$ 900$ raise. He does not find that experience mediates this preference.

\section{DATA}

We developed an approximately 15 -minute survey focusing on teachers' knowledge of, preparation for, and preferences around retirement. We adapted questions from two of the 2018 Health and Retirement Study's survey modules: the Retirement and Pension Plan module and the Retirement and Social Security module. The following section will go into greater detail regarding our retirement stated preferences questions. The survey also included previously validated scales designed to measure financial literacy, personality, numeracy, and risk tolerance (Frederick, 2005; John et al., 1991; Kimball et al., 2008; Lipkus et al., 2001; Lusardi \& Mitchell, 2011; Toplak et al., 2014).

We collect data from the RAND Corporation's nationally representative American Teacher Panel (ATP); survey administration was between February 10 and March 16, 2020. The ATP includes approximately 29,000 active respondents teaching in public K-12 schools. Teachers are recruited to the ATP using probabilistic sampling methods. The ATP drew a random sample of schools and purchased schools' rosters of teachers from a vendor before randomly sampling teachers within those schools to invite to participate in the panel (Robbins et al., 2018). For our study, we invited a total of 9,904 teachers and obtained a response rate of 55 percent. Our sample included both a nationally representative sample of teachers as well as samples representative of 
the following seven areas: Arkansas, California, Florida, Georgia, New York State, New York City, and Texas.

The final sample included 5,464 completed responses surveys. From these, we excluded respondents from our analytical sample if they reported extreme values related to earnings, birthyears, age when entering the teaching workforce, or experience in- and out-of-state. ${ }^{4}$ With these restrictions in place, our analysis sample consisted of 5,111 respondents. Respondents were compensated for their time at a rate of $\$ 1$ per minute of the expected time to complete the survey for a total of $\$ 15$.

\section{Survey Questions and Scales}

Our survey includes several previously validated scales to explore potential heterogeneity in respondents' willingness-to-pay for different job characteristics. We use measures for respondent's cognitive ability and level of conscientiousness. These scales serve as proxies for teacher quality (Cheng \& Zamarro, 2018; Hanushek et al., 2018). The constructs are also associated with retirement saving (e.g. Banks \& Oldfield, 2007; Letkiewicz \& Fox, 2014). To measure teachers' cognitive ability, we include the 8 item Lipkus Numeracy Scale (Lipkus et al., 2001) and the 5 item Cognitive Reflection Test (Frederick, 2005; Toplak et al., 2014). Correct responses are counted to build two measures of cognitive ability, which we combine using a factor analysis with a varimax (orthogonal) rotation. We retain a single factor where both measures load equally. To measure how conscientious teachers are, our survey includes the 44 item Big 5 inventory for personality traits (John et al., 1991). ${ }^{5}$ Responses to the Big 5 questions are on a 5-

${ }^{4}$ We excluded 5.2 percent of respondents for reporting earnings over $\$ 200,000,5.4$ percent of respondents with reported birthyears prior to $1935,0.4$ percent that had potential ages when entering the teaching workforce (age minus total experience) under age 20 , and 4.7 percent if they reported more experience within their current state of residence than they reported in total. Given that many respondents met more than one exclusion criterion, we removed a total of 6.5 percent of the potential sample.

${ }^{5}$ The Big 5 inventory has been validated in a number of samples (John et al., 2008; John \& Srivastava, 1999). 
point Likert scale. We average responses to the 9 questions that capture conscientiousness to generate a single measure. Larger values indicate higher levels of cognitive ability or conscientiousness.

We measure financial literacy using a 3-question battery from Lusardi and Mitchell (2011). The 3 questions are related to the financial concepts of compounding interest rates, inflation, and "risk diversification." Correctly responding to these questions is associated with a higher likelihood of planning for retirement (Lusardi \& Mitchell, 2007). The 3 questions are multiple choice, and all include an option for "don't know." We consider "don't know" to be an incorrect response and simply count the number of correct responses for each respondent to construct our financial literacy measure.

We also construct a measure of risk tolerance following the work of Kimball et al (2008). Respondents answer 2 or 3 questions with the same prompt. Respondents are asked to pick between two jobs: the first job guarantees lifetime income for the family and the second job would have a 50 percent chance of doubling lifetime income and a 50 percent chance of cutting it by a third. Respondents picking the job with a guaranteed lifetime income are asked if they would take the job guaranteeing lifetime income again or a job where the potential cut to lifetime income is 20 percent. Those that choose the guaranteed lifetime income a second time are asked to pick between the job with the guaranteed income and a job where the potential cut is 10 percent. Conversely, respondents initially indicating that they would prefer the job with a potential income cut of onethird are offered the same guaranteed income as previously, but the second job could result in lifetime income cut by half. Those respondents still willing to take the job with a risky lifetime income are offered the initial same guaranteed income and an uncertain income where the potential cut is 75 percent of their lifetime income. Respondents fall into one of six categories of risk 
tolerance. These categories correspond with the potential lifetime pay cut being less than 10 percent, between 10 and 20 percent, between 20 and 33 percent, 33 percent and 50 percent, 50 percent and 75 percent, and greater than 75 percent.

\section{Sample Descriptive Statistics}

Table 1 contains descriptive statistics for our analytical sample. Over 75 percent of respondents are female. White teachers make up 84 percent of the sample while black and Hispanic teachers each comprise 8 percent of the sample. The average age of our respondents is 44 with a standard deviation of 10 and a half years. The age range of our sample is 24 to 81 . On average, teachers had a total of 15.7 years of experience and 14.7 years of experience within their current state of residence. Using the average age and average total experience as benchmarks, the average teacher in our sample would have started teaching at age 29. Our sample has no first-year teachers but 9 percent of the sample has between zero and five years of experience. Teachers average reported salary is approximately $\$ 63,000$ and a standard deviation of approximately $\$ 22,000$. We classify 44 percent of teachers as teaching in elementary schools and 56 percent in secondary schools. ${ }^{6}$

Our analytic sample uses the top end of the Likert-type conscientious scale frequently, answers 2 or more of the financially literacy questions correctly, and prefers less risky income. Respondents answered, on average, 4.5 of the 8 Lipkus Numeracy questions correctly. Respondents fared worse on the Cognitive Reflections Test with the average number of correct answers at 1.8 out of 5 . On the 1 to 5 conscientiousness scale, respondents rated themselves as

${ }^{6}$ Our sample's descriptive statistics match the general teaching population's descriptive statistics well (Hussar et al., 2020). Our sample has slightly fewer Hispanic teachers than the general population, but also has more white, black, and Asian teachers. Our sample reports a base salary nearly $\$ 6,000$ higher than the general population's average base salary, but this is likely attributable to the fact that our sample is more experienced than the general population. The general population is split relatively evenly between elementary and secondary teachers whereas our sample has a larger share of secondary teachers. Analyses will use probability weights to make our sample nationally representative. 
quite conscientious with an average value of 4.13. The standard deviation on self-reported conscientiousness is 0.55 . Over half of the sample correctly answered all three financial literacy questions, and another 31 percent of the sample answered only one question incorrectly. One third of respondents were unwilling to risk a 10 percent pay cut to double their lifetime income, while another third of the sample would not risk a 20 percent pay cut. A combined 10 percent of the sample would be willing to risk having their lifetime income reduced by a third or higher.

\section{Stated Preferences Experiment}

We use a discrete choice stated preferences experiment following Maestas et al. (2018) and Mas and Pallais (2017) to understand teachers' preferences concerning various job conditions. Stated preferences experiments, also sometimes called a conjoint analysis, originated in marketing but have spread to several other fields (Johnston, 2020). Part of the reason for their growing popularity is their success in predicting actual behavior (for example, see Hainmueller et al., 2015; Wiswall \& Zafar, 2018; Wlömert \& Eggers, 2016).

In our experiment, we repeatedly provide teachers with two hypothetical job offers and ask them to indicate which job they prefer. Each job has eight conditions that can vary: salary, type of retirement plan, the retirement plan's expected salary replacement rate $^{7}$, retirement eligibility age, annual salary growth, class size, health insurance coverage, and Social Security participation ${ }^{8}$. For each hypothetical job offer pair, salary and one other characteristic varies. Respondents are instructed to assume all other job conditions, whether explicitly listed in the job offers or not, are the same.

${ }^{7}$ As explained above, a retiree's replacement rate is the ratio of the retiree's benefit to salary. It is the proportion of salary that benefits "replace." If a retiree earned $\$ 75,000$ as a teacher, a 70 percent replacement rate would yield annual benefits of $\$ 52,500(75,000 * 0.70)$.

${ }^{8}$ Approximately 60 percent of teachers participate in Social Security (Kan \& Aldeman, 2014). 
For each job condition except salary, we chose a baseline value that is either the midpoint of the potential values or the most common real-world value. For example, the baseline value of retirement plan type is FAS, the most common teacher retirement plan type. One of the job offers presented to respondents is always comprised of the baseline values for each non-salary job condition. For the other job offer, we randomly select and vary one of the seven non-salary job conditions and set the remaining six conditions equal to their baseline value. Salaries for both jobs are randomly generated deviations from the respondent's reported current salary.

Each respondent was asked to choose between two randomly selected jobs eight times. To supply to the job offers for the survey, we created a database of 108,000 hypothetical job offer pairs. ${ }^{9}$ Job offers presented to respondents are randomly chosen from our database with replacement, which allows for offers to potentially be repeated in the sample. Individual respondents may be asked to choose among job pairs varying the same job condition more than once and may not see offers varying some of the conditions at all.

We constructed the hypothetical job offers using randomly generated salaries and a randomly selected non-salary job characteristic. Offers are calibrated to prevent one job from strictly dominating the other. For example, a job that offers a 73 percent replacement rate and a $\$ 70,000$ annual salary would strictly dominate another job with a 70 percent replacement rate and a $\$ 68,000$ salary. We assume, other things held equal, that teachers would always choose a job with a higher salary if it also had a higher replacement rate, earlier retirement age, higher salary growth rate, smaller average class size, and additional health insurance. See Appendix A for additional information regarding hypothetical job comparison construction.

\footnotetext{
${ }^{9} \mathrm{We}$ arrived at 108,000 hypothetical job comparisons by multiplying the 8 times a respondent would indicate a job preference times the 13,500 potential respondents. Since we sample from the database with replacement, we increased the number of potential respondents beyond the number of teachers we sent the survey to in order to reduce the incidence of repeated hypothetical job comparisons.
} 
For each job condition, Table 2 contains the wording used to present it in the survey, its potential and baseline values, and information about how often it varied in the survey as well as how often each value was selected. Baseline values for each job condition are noted in the potential values column. The number of times that each job condition was randomly selected to be the one that varies in a job offer is provided in parentheses in the job condition column. Each job condition was selected to vary in a job offer between 5,727 and 5,980 times. The frequency that each job condition value is displayed is in the fourth column. Within each job condition, there is an approximately uniform distribution of display frequencies across condition values.

The final column of table 2 shows the probability that respondents choose a job with a given job condition value. The most substantial threat to the validity of our experimental design is if certain job characteristics dominate (i.e., are always chosen). For example, if respondents always choose jobs with the higher salaries, it would imply that the range for salary was set too high, and we would get very little information from our experiment. However, we saw substantial variation in respondent choices across condition values, indicating that our survey values were well calibrated to yield useful information.

Respondents patterns of choosing across various condition values also matched our expectations. For job conditions with ordered condition values, we expected respondents to be more likely to choose jobs with more favorable values, and that was the observed choosing pattern. For example, respondents chose higher annual salary growth more often as the values increased. Teachers chose job offers with a 2 percent annual salary growth 62 percent of the time and jobs with 8 percent annual salary growth 85 percent of the time. 


\section{ECONOMETRIC APPROACH}

The raw proportions of respondents choosing specific job conditions, presented above, gives us an overall idea of which job attributes teachers prefer, but it does not tell us how much teachers prefer those job attributes. Even though we force respondents to choose jobs at the expense of higher salaries, the simple proportions mask heterogeneity in the gap between the two salary offers. Following the approach of Maestas et al. (2018), we estimate teachers' willingnessto-pay for the seven job conditions previously described.

We assume that teachers choose between a set of jobs based on a latent utility model where unobserved utility is a linear and additively separable function of the jobs' non-salary conditions and the jobs' corresponding salary:

$$
U_{i j t}=\alpha+X_{i j t}^{\prime} \beta+\delta \ln w_{i j t}+\varepsilon_{i j t}
$$

where $U_{i j t}$ is individual $i$ 's latent utility for job choice $j$ in the individual's job choice set $t$. While teachers may weigh several job offers in job choice set $t$, our experiment restricts the set to only two jobs. Within choice sets, only one job condition and salary vary. Non-salary job conditions are $X_{i j t}^{\prime}$ and $w_{i j t}$ is the salary. We use the natural logarithm of salary to facilitate interpretation of our effects as percent changes and since the salary offers in our experiment are tied to teachers' reported salaries and there is substantial heterogeneity in salaries across our national sample and within states due to salary schedules. We assume that $\varepsilon_{i j t}$ is an Extreme Value Type I random variable.

We model the probability that an individual chooses job choice $j$ over job choice $k$ in choice set $t$ as:

$$
P\left(U_{i j t}>U_{i k t}\right)=\Lambda\left[\left(X_{i j t}^{\prime}-X_{i k t}^{\prime}\right) \beta+\delta\left(\ln w_{i j t}-\ln w_{i k t}\right)\right]
$$


where $\Lambda[\cdot]$ denotes the cumulative logistic distribution. We should be able to identify $\beta$ and $\delta$ in equation (2) since each non-salary job condition and salary is randomly selected. Despite our randomization, there could be other state level unobserved differences that are associated with the jobs that our respondents select. For example, most states use FAS plans, which may lead teachers to develop a preference for these plans owing to their familiarity with how these plans function. To account for these differences, we include fixed effects for states. Preferences may also be dynamic based on how many job choices respondents have already made. For example, respondents may be willing to pay to retire at age 57 , but the strength of that preference may differ if respondents have seen a previous job offer with an age 55 retirement age. To combat this type of bias, we also include question fixed effects in some models.

Consider a non-salary job condition $c$ and the marginal utilities for this job condition, $\beta^{c}$, and salary, $\delta$, identified in equation (2). For individual $i$, job offer $j$ in choice set $t$ that included job condition $c$ has expected utility $E\left(U_{i j t}\right)=\beta^{c}+\delta \ln w_{i j t}$ and job offer $k$ in the same choice set that does not have the job condition has expected utility $E\left(U_{i k t}\right)=\delta \ln w_{i k t}$. An individual is indifferent between the two jobs when we fix the salary at $w$ and subtract off the individual's willingness-to-pay for the job condition:

$$
\delta \ln w=\beta^{c}+\delta \ln \left(w-W T P^{c}\right)
$$

where the $W T P^{c}$ is the willingness-to-pay for job condition $c$. We solve for $W T P^{c}$ in equation (3) to derive our willingness-to-pay measure:

$$
W T P^{c}=w\left[1-\exp \left(-\frac{\beta^{c}}{\delta}\right)\right]
$$

We report willingness-to-pay estimates as $1-\exp \left(-\frac{\beta^{c}}{\delta}\right)$ and interpret these effects as $100\left[1-\exp \left(-\frac{\beta^{c}}{\delta}\right)\right]$ percent salary increases a respondent is willing to forgo to receive job 
attribute $c$. We use the delta method to calculate standard errors in equation (4) and cluster the standard errors for each respondent. Statistical inference tests the null hypothesis that the willingness-to-pay estimates are different from zero; under this null hypothesis, respondents would be indifferent to the job condition. We include probability weights to ensure our sample is nationally representative

Our decision to predefine the relationships between several job conditions and salary to avoid dominant offers has an important implication for our willingness-to-pay measure. By construction, willingness-to-pay estimates for increasing replacement rate, increasing salary growth, and adding dental and optical coverage to health insurance plans will be positive and estimates increasing the retirement age, increasing class size, and health insurance plans that cover a lower share of costs will be negative. The statistical significance and magnitudes of the willingness-to-pay estimates for these job conditions are still policy relevant despite the predefined signs on estimates.

We investigate heterogeneity in willingness-to-pay for job conditions based on respondents' experience, cognitive ability, levels of conscientiousness, financial literacy, and risk tolerance. To do so, we interact the differences in job conditions for a choice set with experience, cognitive ability, conscientiousness, financial literacy, and risk tolerance in equation (2).

Estimates of these interaction terms would represent the differential effect of teachers' preferences for the job condition for teachers not in the reference group for these mediators relative to teachers in the reference group. To translate this differential into a willingness-to-pay estimate, we add the interaction term to the reference group's preference in the numerator of the exponential in equation (4). For example, the willingness-to-pay for an early-career teacher, denoted by the superscript $e$, for job condition $c$ is $W T P^{c e}=w\left[1-\exp \left(-\frac{\beta^{c}+\beta^{c e}}{\delta}\right)\right]$ where $\beta^{c e}$ is the differential 
preference of the job condition for early-career teachers. We interpret this effect similarly to the overall effect.

\section{Results}

We begin with the results from our stated preferences experiment that compare teachers' willingness-to-pay for different retirement plan types. Table 3 contains overall willingness-to-pay estimates for DC and CB plans relative to FAS plans. These values are calculated using the nonlinear transformation in equation (4) based on the estimates from the logit model in equation (2).

The first column is our base specification while the second column includes question fixed effects to control for changes in willingness-to-pay as respondents answer more questions. In column 3, we include state fixed effects to control for any residual variation in preferences that could be correlated with respondents' state of residence retirement systems options. Column 4 includes both state and question fixed effects. We prefer the model in column 4 since we expect heterogeneity across states and questions.

Our results indicate that, on average, respondents would need to be compensated with a 2.7 percent pay increase to be indifferent between being enrolled in a DC plan versus a FAS plan. Similarly, we estimate that respondents would be indifferent between a CB plan and a FAS plan if the $\mathrm{CB}$ plan were paired with a 1.9 percent salary increase. All estimates are statistically different from zero at the 99 percent confidence level.

Our experimental design sought to minimize bias from preconceived notions about various plan types as well as differences in plan generosity in two ways. First, we did not identify the retirement plan types by their common names (e.g., defined contribution). Instead, we described how teachers would earn benefits under each type of plan and asked them to choose based on the description. 
Second, respondents were told that the plans were expected to deliver similar benefits at retirement. Specifically, they were instructed that, for both the FAS and alternative plans, retirement benefits would be expected to replace 70 percent of their end of career salary, that they would be eligible to retire with full benefits at age 60, and that they would be enrolled in Social Security. The only differences between retirement plan types were how respondents earn benefits and the risk respondents perceive is associated with each type of plan based solely on the plan's description, both of which are addressed in our plan descriptions.

In contrast to some of the previous literature (DeArmond \& Goldhaber, 2010; Johnston, 2020), our results indicate that respondents place some value on, or have more comfort with, the way benefits accrue under a FAS plan and/or perceive alternative plans as being somewhat riskier. While we find that teachers would need to be compensated to be indifferent between FAS plans and alternative plan types, our results suggest that teachers may be open to plan design change if paired with modest salary increases.

Owing to the backloaded nature of FAS plans, there is likely heterogeneity in willingnessto-pay for retirement plan types based on experience. Table 4 presents willingness-pay-estimates for enrolling in alternative retirement plan types instead of traditional FAS plans mediated by experience. We group respondents based on experience quartiles: respondents in the first experience quartile (termed "early-career") have 8 or fewer years of experience, respondents in the second and third quartiles (termed "mid-career") have between 9 and 21 years of experience, and fourth quartile respondents (termed "late-career") have 22 or more years of experience.

We find that teachers' willingness-to-pay for a FAS plan relative to either alternative retirement plan increases with experience. Respondents designated as early-career (lowexperience) are indifferent between enrolling in either a DC or a CB plan rather than a traditional 
FAS plan. Mid-career respondents would need to be compensated with a 2.7 percent pay increase to be indifferent between a DC and FAS plan, while a 2 percent pay increase would be required for a CB plan. Late-career respondents, unsurprisingly, had the strongest preference for FAS plans. Our results indicate that late-career teachers would equate enrolling in a DC plan with a 4.8 percent pay cut, while enrolling in a CB plan is equivalent to a 4.3 percent pay cut.

This observed pattern of heterogeneity in willingness-to-pay coincides with the backloaded nature of FAS plans. Teachers often do not earn substantial benefits under a FAS plan until they approach the retirement eligibility. Late-career respondents who have accrued the most benefits would have the strongest preferences for FAS plans. New and early-career teachers, who have not yet earned valuable pension benefits, are indifferent among the plan types.

\section{Relative Valuation of Retirement Plan Types and Other Job Characteristics}

Policymakers face numerous tradeoffs when designing teachers' compensation packages, and no element exists in a vacuum. When weighing these various tradeoffs, it is important to understand teachers' relative preferences across job characteristics. This section provides willingness-to-pay estimates for the other 7 job attributes in our experiment and relates those preferences to our estimates for retirement plan type.

There are at least two reasons why the relative willingness-to-pay estimates provided in this section are important. First, our main results provide estimates for the required raises to compensate teachers for enrolling in alternative retirement plans instead of FAS plans. However, states or school districts could choose to compensate teachers via changes to other retirement plan features or job characteristics (e.g., replacement rates or the retirement age).

Second, policymakers facing budget shortfalls may have to consider making changes to teacher compensation without giving anything to teachers in exchange. Proponents of FAS plans 
argue that policymakers should protect these plans and make budget cuts elsewhere. When faced with such decisions, comparing willingness-to-pay estimates for retirement plans versus other job characteristics gives policymakers helpful information about teachers' relative valuations of various elements of teachers' compensation packages.

Table 5 provides willingness-to-pay estimates for the other 7 job attributes we included in our experiment (column 1). The table also includes estimates for how much each job characteristic would need to change to make teachers indifferent between alternative plan types and a FAS plan (columns 2 and 3). ${ }^{10}$ All estimates in this table come from our preferred model that includes state and question fixed effects.

Since states that may undertake retirement reform are likely to enroll all new hires and may enroll early-career teachers into an alternative plan design, we evaluate willingness-to-pay heterogeneity based on experience for the other job conditions in our experiment and report results for salary growth and health insurance in Table $6 .{ }^{11}$ This table is analogous to Table 5 . The panels correspond to different job conditions from the experiment.

In table 5, we estimate that a one percentage point replacement rate increase in retirement is equivalent to a 1.6 percent salary increase. This estimate implies that respondents would be indifferent between enrolling in a DC plan if they are compensated with replacement rate that is 1.7 percentage points higher than the replacement rate in a corresponding FAS plan. Within our

${ }^{10}$ We say that a respondent would be indifferent between enrolling in an alternative retirement plan instead of a FAS plan if the alternative plan is paired with some change in another job attribute. Formally, let $W T P^{P T}$ represent the willingness-to-pay for either alternative plan design. A respondent is indifferent between taking a job with an alternative retirement plan if the job also came with some other altered job condition $c$, WTP $P^{P T}+\gamma^{c} W T P^{c}=0$, where $\gamma^{c}$ represents how much the corresponding job condition changes. The relative valuation of plan type willingness-to-pay for retirement plan type is then $\gamma^{c}=-\left(\frac{W T P^{P T}}{W T P^{C}}\right)$. To compensate teachers for enrolling in non-FAS plans with changes in non-salary job attributes, willingness-to-pay estimates for non-salary job attributes are inversely related to how much the non-salary job attribute would have to change. In other words, the less respondents value a job characteristic, the more it would have to change to offset enrolling in a FAS-alternative instead of FAS plans.

${ }^{11}$ We do not find evidence of heterogeneity based on experience in willingness to pay for replacement rate, retirement age, class size, or Social Security. These results are available upon request. 
experiment's context, the DC plan would replace 71.7 percent of salary whereas the FAS plan would replace 70 percent. The corresponding compensating differential for a CB plan would be a 1.2 percentage point replacement rate increase. Early-career respondents would be indifferent between enrolling in a DC plan if it came with a half percentage point increase in full retirement replacement rate relative to a competing FAS plan and would be indifferent between CB and FAS if the CB plan had a 0.2 percent lower replacement rate.

We estimate that teachers would be indifferent between lowering the retirement age by one year and a 2.4 percent salary increase. This estimate implies that teachers would also be indifferent between retiring 1.3 and 0.79 years earlier if they were to enroll in a DC or CB plan, respectively, as opposed to a FAS plan. In other words, teachers would be willing to enroll in an alternative plan if that plan reduces their expected retirement age by one year relative to a FAS plan. Given our experiments' parameters, this means teachers enrolled in DC or CB plans would expect to retire at age 59 rather than our baseline FAS plan's retirement age of 60. Early-career respondents would be willing to enroll in a DC plan that has a retirement age 0.33 years earlier than a FAS plan's retirement age. To enroll in a CB plan, early-career respondents would forgo retirement by 0.13 years.

Policy propositions to switch retirement plan types could also compensate teachers with higher rates of salary growth or with reduced class sizes, both of which teachers and teachers' unions commonly call on state and local policymakers to do (e.g., Weingarten, 2019a, 2019b). Our respondents are willing to pay 5.7 percent of salary for a one percentage point increase in their annual salary growth rate and 0.5 percent of salary to decrease average class sizes by one student.

As shown in column 2, teachers would be indifferent between enrolling in a DC plan instead of a FAS plan if the DC plan was coupled with a 0.47 percentage point increase in their 
salary growth rate or a 5.4 student reduction in their average class size. The $\mathrm{CB}$ equivalent valuations are increasing the rate of salary growth by a third of a percentage point or reducing class sizes by 3.8 students.

Our estimates in panel A of table 6 indicate that respondents' willingness-to-pay for salary growth decreases with experience, but required compensating differentials in terms of salary growth continue to increase with experience. Mid-career respondents would be indifferent between enrolling in a FAS-alternative retirement plan if it was associated with between a 0.35 and 0.47 percentage point higher salary growth rate than the salary growth rate associated with a FAS plan. These compensating differentials rise to nearly 1 percentage point of salary growth for late-career respondents.

Overall estimates in table 5 show that the teachers in our sample place a higher value on how much an insurance plan covers expected healthcare costs and whether they have optical and dental coverage than they place on the type of retirement plan in which they enroll. We estimate that teachers would require a 16.8 percent salary increase to offset a healthcare plan that covers 60 percent of expected costs instead of a plan that covers 80 percent of costs. Respondents are also indifferent between a 10.6 percent raise and enrolling in a plan with dental and optical coverage. ${ }^{12}$

We uncover heterogeneity in willingness-to-pay for health insurance in panels B and C of table 6. Respondents with more experience are willing to pay more for a health insurance plan that covers a larger share of health care costs, but mid-career teachers are willing to pay the most for dental and optical coverage. Regardless of experience, willingness-to-pay estimates for health insurance is greater than 10 percent of salary.

\footnotetext{
${ }^{12} \mathrm{We}$ do not report the DC and CB relative valuations in tables 5 and 6 for health insurance and Social Security since these job attributes are not defined continuously in our experiment. The relative valuations would be the willingness-to-pay for retirement plan type as a proportion of willingness-to-pay for health insurance or Social Security, which is not all that informative of a measure.
} 
Finally, teachers in our sample place a larger value on enrolling in Social Security than they do on which type of other retirement plan they are enrolled in. Column 1 of table 5 shows that respondents are willing to pay 10.7 percent of salary to be enrolled in Social Security. This willingness-to-pay is especially noteworthy since it exceeds the employer contribution rate to Social Security of 6.2 percent. In other words, the cost to employers to enroll teachers in Social Security is 4.5 percentage points lower than how much teachers value Social Security.

Willingness-to-pay for Different Retirement Plan Types Mediated by Cognitive Ability, Conscientiousness, Financial Literacy, and Risk Tolerance

We estimate the retirement plan type willingness-to-pay distributions for respondents with differing levels of cognitive ability, conscientiousness, financial literacy, and risk tolerance. These results are in Table 7. We report estimates from our preferred specification that include state and question fixed effects. Columns 1 and 4 show the estimates for respondents in the "low" category for each mediator. Columns 2 and 5 contain estimates for respondents in the "medium" category for each mediator. Columns 3 and 6 provide estimates of willingness-to-pay for respondents in the "high" category for each mediator.

Using cognitive ability to proxy for teacher quality, we find significant heterogeneity in willingness-to-pay for retirement plan type. We group respondents by cognitive ability based on respondents' quartile in the cognitive ability distribution. As cognitive ability increases, teachers' willingness-to-pay for DC plans decreases. Teachers in the bottom cognitive ability quartile are indifferent between switching from FAS plans to either a DC or CB plan, while teachers in the top quartile value these plans at a 4.6 or 3.1 percent pay cut, respectively. Even though willingnessto-pay estimates mediated by experience and cognitive ability appear similar in both magnitude 
and direction, there does not appear to be any relationship between these mediators in our sample: the correlation between experience and cognitive ability is negative $0.01 .^{13}$

Our second proxy for teacher quality, self-reported conscientiousness, does not explain much heterogeneity in plan type willingness-to-pay. Apart from low-conscientiousness respondents' willingness-to-pay for $\mathrm{CB}$ plans, respondents value enrolling in DC and CB plans instead of FAS plans at between a 2 and 3 percent pay reduction.

We also group respondents based on the number of financial literacy questions they answer correctly. Low-financial literacy respondents answer 0 or 1 of the 3 financial literacy questions correctly. Medium-financial literacy respondents correctly answer 2 of the 3 financial literacy questions, and high-financial literacy respondents answer all 3 financial literacy questions correctly. $^{14}$

The most financially literate teachers in our sample are willing to pay more for traditional pension plans. Respondents answering all 3 financial literacy questions correctly are willing to pay 3.9 percent and 3.4 percent of salary for a FAS plan rather than switch to DC or CB plans, respectively. Teachers displaying the lowest levels of financial literacy are indifferent between retirement plans. Moderately financially literate teachers are indifferent between FAS and CB plans, but are willing to pay 2.2 percent of salary for FAS over DC plans.

We group respondents based on which potential lifetime pay cut they would be willing to accept from our risk tolerance questions. The questions making up our risk tolerance scale asked

\footnotetext{
${ }^{13}$ We also conduct Pearson's chi-squared test of independence to assess if there is a relationship between experience and cognitive ability within our low, medium, and high groupings of experience and cognitive ability based on quartiles. We fail to find any evidence that the two mediators are related to one another: the p-value from this test is 0.303 .

${ }^{14}$ Per the descriptive statistics in Table 1, approximately 17 percent of respondents would fall in the lowfinancial literacy group, 31 percent would fall into the medium-financial literacy group, and the remaining 53 percent would be high-financial literacy. Similarly, we consider one third of respondents to have low-risk tolerance, another third to be medium risk-tolerance, and the remaining third to be high-risk tolerance.
} 
respondents if they would risk taking a job with a varying pay cut to lifetime income in exchange for the potential to double their lifetime income. Low-risk tolerance respondents are unwilling to accept the job if the potential cut to respondents' lifetime income is less than 10 percent, while medium-risk tolerance respondents are willing to accept the job if the potential lifetime income cut is between 10 and 20 percent. High-risk tolerance respondents are willing to accept the job even if the potential cut to respondents' lifetime income is greater than 20 percent. ${ }^{15}$

We do not find much evidence of heterogeneity based on risk tolerance in willingness-topay retirement plan types. Respondents with higher levels of risk tolerance are willing to pay less for traditional FAS plans than respondents with lower levels of risk tolerance. Medium risk tolerance respondents have the highest willingness-to-pay estimates for both alternative plan types.

\section{CONCLUSION}

Teacher pensions are underfunded by more than $\$ 600$ billion in the aggregate (McGee, 2019; Novy-Marx \& Rauh, 2011). More resources than ever before are being devoted to paying down pension debt (Costrell, 2020), squeezing state and local education budgets (McGee, 2016; Nation, 2018). What's more, there is mounting evidence that traditional pension plans do not work well for all teachers (Aldeman \& Johnson, 2015; Backes et al., 2016; Costrell \& Podgursky, 2009). As a result, policymakers are exploring alternative retirement plan designs. However, advocates for traditional pensions often stymie consideration of alternative plans citing teachers' strong preferences for final average salary pensions. Unfortunately, up until now little was know about teachers' preferences around retirement or strength of those preferences relative to other aspects of their jobs and compensation.

\footnotetext{
${ }^{15}$ Based on the descriptive statistics in Table 1, we consider one third of respondents to have low-risk tolerance, another third to be medium risk-tolerance, and the remaining third to be high-risk tolerance.
} 
This paper addresses this knowledge gap by developing willingness-to-pay estimates based on a stated preferences experiment embed in a nationally representative survey of public K-12 school teachers. We find that teachers are indifferent between a traditional pension and alternative plan designs when the alternatives are paired with a 2.7 and 1.9 percent pay increase. This finding differs somewhat from other literature on teachers' retirement preferences that finds teachers may prefer 401(k)-style plans, but the extant literature only considers more localized context of a simgle state or school dirtrict (DeArmond \& Goldhaber, 2010; Johnston, 2020). Corroborating previous literature, however, we find that experience mediates retirement plan preferences. While more experienced teachers prefer FAS plans, early-career teachers are indifferent between traditional pensions and alternative plans.

We also show that teachers place sizable values on other job conditions. Teachers are willing to trade salary today if it means that their expected retirement benefits will be larger or if they can retire at a younger ages. They also place a substantial value on being enrolled in Social Security. In fact, we estimate that teachers have stronger preferences around their expected retirement benefit, retirement age, and Social Security enrollment than they do for various retirement plan types.

While our results have the potential to inform policy decisions, there is one key limitation. Teachers' stated preferences on a 15-minute survey may differ from their true or revealed preferences. There is a literature that finds that stated preferences experiments tend to match revealed preferences in other populations (e.g., Hainmueller et al., 2015; Wiswall \& Zafar, 2018; Wlömert \& Eggers, 2016), but none of this previous literature involves teachers or retirement plan specifically. 
With this limitation in mind, our estimates provide some insights that may be valuable to policymakers as they grapple with current budgetary challenges. For example, states could reduce future budgetary risk by placing new teachers in alternative retirement plans and at the same time offering modest pay raises. In addition, changes to retirement age, expected retirement benefits, and healthcare coverage are likely to result in larger negative labor market consequences than retirement plan design changes. Our results also indicate that states whose teachers are not currently covered by Social Security could reap significant benefit from enrolling them in the program because teachers appear to value those benefits more than their cost.

States and school districts that face challenging budget situations may have to make difficult decisions that affect teachers' job conditions, pay, and benefits. Understanding how teachers value various aspects of their jobs and compensation can help inform these policy decisions and minimize potential negative consequences. 


\section{REFERENCES}

Aldeman, C., \& Johnson, R. W. (2015). Negative Returns: How State Pensions Shortchange Teachers [Policy Report]. Bellwether Education Partners and Urban Institute. https://www.teacherpensions.org/sites/default/files/TeacherPensions_Negative\%20Return s_Final.pdf

Backes, B., Goldhaber, D., Grout, C., Koedel, C., Ni, S., Podgursky, M., Xiang, P. B., \& Xu, Z. (2016). Benefit or Burden? On the Intergenerational Inequity of Teacher Pension Plans. Educational Researcher, 45(6), 367-377. https://doi.org/10.3102/0013189X16666812

Banks, J., \& Oldfield, Z. (2007). Understanding Pensions: Cognitive Function, Numerical Ability and Retirement Saving*. Fiscal Studies, 28(2), 143-170. https://doi.org/10.1111/j.14755890.2007.00052.x

Biasi, B. (2019). Higher Salaries or Higher Pensions? Inferring Preferences from Teachers' Retirement Behavior [Working Paper]. https://doi.org/10.2139/ssrn.3058384

Boivie, I. (2011). The Three Rs of Teacher Pension Plans: Recruitment, Retention, and Retirement [Issue Brief]. National Institute on Retirement Security. https://www.nirsonline.org/reports/the-three-rs-of-teacher-pension-plans-recruitmentretention-and-retirement/

Boivie, I. (2017). Revisiting the Three Rs of Teacher Retirement: Recruitment, Retention and Retirement [Issue Brief]. National Institute on Retirement Security. https://www.nirsonline.org/reports/revisiting-the-three-rs-of-teacher-retirement-systemsrecruitment-retention-and-retirement/ 
Brown, K. M. (2013). The link between pensions and retirement timing: Lessons from California teachers. Journal of Public Economics, 98, 1-14. https://doi.org/10.1016/j.jpubeco.2012.10.007

Cheng, A., \& Zamarro, G. (2018). Measuring teacher non-cognitive skills and its impact on students: Insight from the Measures of Effective Teaching Longitudinal Database. Economics $\quad$ Education $\quad$ Review, 251-260. https://doi.org/10.1016/j.econedurev.2018.03.001

Chingos, M. M., \& West, M. R. (2015). Which Teachers Choose a Defined Contribution Pension Plan? Evidence from the Florida Retirement System. Education Finance and Policy, 10(2), 193-222. https://doi.org/10.1162/EDFP_a_00158

Costrell, R. M. (2019). Reforming Teacher Pension Plans: The Case of Kansas, the 1st Teacher Cash Balance Plan. In EdWorkingPapers.com (EdWorkingPaper No. 19-92). Annenberg Institute at Brown University. https://www.edworkingpapers.com/ai19-92

Costrell, R. M. (2020). Employer Contributions Per Pupil for Retirement Benefits: U.S. Public Elementary and Secondary Schools, teachers \& other employees, 2004-2020. https://edre.uark.edu/_resources/pdf/costrellemployercontributionsperpupil.pdf

Costrell, R. M., \& McGee, J. B. (2010). Teacher Pension Incentives, Retirement Behavior, and Potential for Reform in Arkansas. Education Finance and Policy, 5(4), 492-518. https://doi.org/10.1162/EDFP_a_00013

Costrell, R. M., \& Podgursky, M. (2009). Peaks, Cliffs, and Valleys: The Peculiar Incentives in Teacher Retirement Systems and Their Consequences for School Staffing. Education Finance and Policy, 4(2), 175-211. https://doi.org/10.1162/edfp.2009.4.2.175 
Dadayan, L. (2020, July 1). COVID-19 Pandemic Could Slash 2020-21 State Revenues By \$200 Billion. Tax Policy Center. https://www.taxpolicycenter.org/taxvox/covid-19-pandemiccould-slash-2020-21-state-revenues-200-billion

DeArmond, M., \& Goldhaber, D. (2010). Scrambling the Nest Egg: How Well Do Teachers Understand Their Pensions, and What Do They Think about Alternative Pension Structures? Education Finance and Policy, 5(4), 558-586. https://doi.org/10.1162/EDFP_a_00010

Fitzpatrick, M. D. (2015). How Much Are Public School Teachers Willing to Pay for Their Retirement Benefits? American Economic Journal: Economic Policy, 7(4), 165-188. https://doi.org/10.1257/pol.20140087

Frederick, S. (2005). Cognitive Reflection and Decision Making. Journal of Economic Perspectives, 19(4), 25-42. https://doi.org/10.1257/089533005775196732

Goldhaber, D., \& Grout, C. (2016). Which plan to choose? The determinants of pension system choice for public school teachers*. Journal of Pension Economics \& Finance, 15(1), 3054. https://doi.org/10.1017/S1474747214000353

Goldhaber, D., Grout, C., \& Holden, K. L. (2017). Pension Structure and Employee Turnover: Evidence from a Large Public Pension System. ILR Review, 70(4), 976-1007. https://doi.org/10.1177/0019793916678424

Goldhaber, D., \& Holden, K. (2020). How Much do Teachers Value Deferred Compensation? Evidence from Defined Contribution Rate Choices (CALDER Working Paper No. 2420920). https://caldercenter.org/sites/default/files/WP\%20242-0920\%20FINAL.pdf 
Hainmueller, J., Hangartner, D., \& Yamamoto, T. (2015). Validating vignette and conjoint survey experiments against real-world behavior. Proceedings of the National Academy of Sciences, 112(8), 2395-2400. https://doi.org/10.1073/pnas.1416587112

Hanushek, E. A., Piopiunik, M., \& Wiederhold, S. (2018). The Value of Smarter Teachers: International Evidence on Teacher Cognitive Skills and Student Performance. Journal of Human Resources, 0317-8619R1. https://doi.org/10.3368/jhr.55.1.0317.8619R1

Horng, E. L. (2009). Teacher Tradeoffs: Disentangling Teachers' Preferences for Working Conditions and Student Demographics: American Educational Research Journal. https://doi.org/10.3102/0002831208329599

Hussar, B., Zhang, J., Hein, S., Wang, K., Roberts, A., Cui, J., Smith, M., Mann, F. B., Barmer, A., \& Dilig, R. (2020). The Condition of Education 2020. (NCES 2020-144). National Center for Education Statistics, Institute for Education Sciences, U.S. Department of Education.

John, O. P., Donahue, E. M., \& Kentle, R. L. (1991). The big five inventory-Versions 4a and 54.

John, O. P., Naumann, L. P., \& Soto, C. J. (2008). Paradigm shift to the integrative big five trait taxonomy. Handbook of Personality: Theory and Research, 3(2), 114-158.

John, O. P., \& Srivastava, S. (1999). The Big Five trait taxonomy: History, measurement, and theoretical perspectives. Handbook of Personality: Theory and Research, 2(1999), 102138.

Johnson, S. M., Kraft, M. A., \& Papay, J. P. (2012). How context matters in high-need schools: The effects of teachers' working conditions on their professional satisfaction and their students' achievement. Teachers College Record, 114(10), 1-39. 
Johnston, A. C. (2020). Teacher Preferences, Working Conditions, and Compensation Structure. In EdWorkingPapers.com (EdWorkingPaper No. 20-202). Annenberg Institute at Brown University. https://doi.org/10.26300/hr7y-1137

Kan, L., \& Aldeman, C. (2014). Uncovered: Social Security, Retirement Insecurity, and 1 Million Teachers [Policy Report]. Bellwether Education Partners.

Kim, D., Koedel, C., \& Xiang, P. B. (2020). The trade-off between pension costs and salary expenditures in the public sector. Journal of Pension Economics \& Finance, 1-18. https://doi.org/10.1017/S1474747219000362

Kimball, M. S., Sahm, C. R., \& Shapiro, M. D. (2008). Imputing Risk Tolerance from Survey Responses. Journal of the American Statistical Association, 103(483), 1028-1038. JSTOR.

Ladd, H. F. (2011). Teachers' Perceptions of Their Working Conditions: How Predictive of Planned and Actual Teacher Movement? Educational Evaluation and Policy Analysis, 33(2), 235-261. https://doi.org/10.3102/0162373711398128

Letkiewicz, J. C., \& Fox, J. J. (2014). Conscientiousness, Financial Literacy, and Asset Accumulation of Young Adults. Journal of Consumer Affairs, 48(2), 274-300. https://doi.org/10.1111/joca.12040

Lipkus, I. M., Samsa, G., \& Rimer, B. K. (2001). General performance on a numeracy scale among highly educated samples. Medical Decision Making, 21(1), 37-44.

Lusardi, A., \& Mitchell, O. (2007). Financial literacy and retirement planning: New evidence from the Rand American Life Panel (CFS Working Paper Series No. 2007/33). Center for Financial Studies (CFS). https://econpapers.repec.org/paper/zbwcfswop/200733.htm 
Lusardi, A., \& Mitchell, O. S. (2011). Financial literacy around the world: An overview. Journal of Pension Economics \& Finance, 10(4), 497-508. https://doi.org/10.1017/S1474747211000448

Maestas, N., Mullen, K. J., Powell, D., von Wachter, T., \& Wenger, J. B. (2018). The Value of Working Conditions in the United States and Implications for the Structure of Wages (Working Paper No. 25204). National Bureau of Economic Research. https://doi.org/10.3386/w25204

Mas, A., \& Pallais, A. (2017). Valuing Alternative Work Arrangements. American Economic Review, 107(12), 3722-3759. https://doi.org/10.1257/aer.20161500

McGee, J. B. (2016). Feeling the Squeeze: Pension Costs Are Crowding Out Education Spending (No. 22). Manhattan Institute. https://www.manhattan-institute.org/html/feeling-squeezepension-costs-are-crowding-out-education-spending-9368.html

McGee, J. B. (2019). How to Avert a Public-Pension Crisis (No. 40). National Affairs. https://www.nationalaffairs.com/publications/detail/how-to-avert-a-public-pension-crisis

McGee, J. B., \& Winters, M. A. (2017). How Pensions Contribute to the Premium Paid to Experienced Public School Teachers. Educational Researcher, 46(5), 250-258. https://doi.org/10.3102/0013189X17721906

McGee, J. B., \& Winters, M. A. (2018). Rethinking the Structure of Teacher Retirement Benefits: Analyzing the Preferences of Entering Teachers: Educational Evaluation and Policy Analysis. https://doi.org/10.3102/0162373718798488

Nation, J. (2018). Pension Math: Public Pension Spending and Service Crowd Out in California, 2003-2030 (Working Paper No. 17-023). Stanford Institute for Economic Policy Research. 
https://siepr.stanford.edu/research/publications/pension-math-public-pension-spendingand-service-crowd-out-california-2003

Novy-Marx, R., \& Rauh, J. (2011). Public Pension Promises: How Big Are They and What Are They Worth? The Journal of Finance, 66(4), 1211-1249. https://doi.org/10.1111/j.15406261.2011.01664.x

Public Plans Data. (2020). Center for Retirement Research at Boston College, Center for State and Local Government Excellence, and National Association of State Retirement Administrators. https://crr.bc.edu/data/public-plans-database/

Robbins, M. W., Grimm, G., Stecher, B., \& Opfer, V. D. (2018). A Comparison of Strategies for Recruiting Teachers Into Survey Panels: SAGE Open. https://doi.org/10.1177/2158244018796412

Snyder, T., D., de Brey, C., \& Dillow, S. A. (2019). Digest of Education Statistics 2017 (NCES 2018-070). National Center for Education Statistics, Institute for Education Sciences, U.S. Department of Education.

State Board of Administration of Florida. (2020). Fact Sheet: Update on Choice in the Florida Retirement System. https://www.sbafla.com/fsb/Portals/FSB/Content/Performance/20200630_UpdateOnFRS PlanChoice.pdf?ver=2020-07-28-142624-503

Toplak, M. E., West, R. F., \& Stanovich, K. E. (2014). Assessing miserly information processing: An expansion of the Cognitive Reflection Test. Thinking \& Reasoning, 20(2), 147-168. https://doi.org/10.1080/13546783.2013.844729

U.S. Bureau of Labor Statistics. (2019). National Compensation Survey: Employee Benefits in the United States, March 2019. 
Viano, S., Pham, L., Henry, G. T., Kho, A., \& Zimmer, R. (2019). Push or Pull: School-Level Factors That Influence Teacher Mobility in Turnaround Schools. In EdWorkingPapers.com (EdWorkingPaper No. 19-146). Annenberg Institute at Brown University. https://doi.org/10.26300/aknp-g506

Weingarten, R. (2019a, February 27). AFT President Randi Weingarten on Federal Legislation to Reduce Class Sizes [Press Release]. https://www.aft.org/press-release/aft-president-randiweingarten-federal-legislation-reduce-class-sizes

Weingarten, R. (2019b, May 6). AFT's Weingarten Responds to Betsy DeVos on Teacher Salaries [Press Release]. https://www.aft.org/press-release/afts-weingarten-responds-betsy-devosteacher-salaries

Wiswall, M., \& Zafar, B. (2018). Preference for the Workplace, Investment in Human Capital, and Gender. The Quarterly Journal of Economics, 133(1), 457-507. https://doi.org/10.1093/qje/qjx035

Wlömert, N., \& Eggers, F. (2016). Predicting new service adoption with conjoint analysis: External validity of BDM-based incentive-aligned and dual-response choice designs. Marketing Letters, 27(1), 195-210. https://doi.org/10.1007/s11002-014-9326-X 


\section{FigURES}

Figure 1: Example of Two Job Offers

\section{AMERICAN \\ TEACHER \\ ¿ PANEL}

Imagine you are offered two teaching jobs shown below. Except for the highlighted characteristic(s), please assume the jobs are the same in all other ways, including on characteristics not listed in the table.

Please review the jobs and indicate below whether you prefer Job A or Job B.

\begin{tabular}{|c|c|c|}
\hline & Job A & Job B \\
\hline $\begin{array}{l}\text { Salary } \\
\text { Growth }\end{array}$ & Salary grows by 5 percent annually. & Salary grows by 5 percent annually. \\
\hline $\begin{array}{l}\text { Type of } \\
\text { Retirement } \\
\text { Plan }\end{array}$ & $\begin{array}{l}\text { The retirement plan bases benefits on a formula involving a } \\
\text { person's age, years of service, and salary. }\end{array}$ & $\begin{array}{l}\text { The retirement plan bases benefits on a formula involving a } \\
\text { person's age, years of service, and salary. }\end{array}$ \\
\hline $\begin{array}{l}\text { Replacement } \\
\text { Rate }\end{array}$ & $\begin{array}{l}\text { A teacher who works a full career in the same retirement } \\
\text { system earns retirement benefits that would provide a monthly } \\
\text { check equivalent to } 70 \text { percent of their end-of-career salary. }\end{array}$ & $\begin{array}{l}\text { A teacher who works a full career in the same retirement } \\
\text { system earns retirement benefits that would provide a monthly } \\
\text { check equivalent to } 70 \text { percent of their end-of-career salary. }\end{array}$ \\
\hline $\begin{array}{l}\text { Retirement } \\
\text { Age }\end{array}$ & $\begin{array}{l}\text { A teacher who works a full career in the same retirement } \\
\text { system is eligible to receive benefits at age } 57 .\end{array}$ & $\begin{array}{l}\text { A teacher who works a full career in the same retirement } \\
\text { system is eligible to receive benefits at age } 60 \text {. }\end{array}$ \\
\hline Class Size & Teachers have class sizes of approximately 18 students. & Teachers have class sizes of approximately 18 students. \\
\hline Health Care & $\begin{array}{l}\text { The health insurance plan would cover } 80 \text { percent of healthcare } \\
\text { costs for the average person and provide catastrophic coverage. }\end{array}$ & $\begin{array}{l}\text { The health insurance plan would cover } 80 \text { percent of healthcare } \\
\text { costs for the average person and provide catastrophic coverage. }\end{array}$ \\
\hline $\begin{array}{l}\text { Social } \\
\text { Security }\end{array}$ & Teachers contribute to and earn benefits in Social Security. & Teachers contribute to and earn benefits in Social Security. \\
\hline Salary & $\$ 98,279$ & $\$ 102,288$ \\
\hline
\end{tabular}

Prefer Job A

Prefer Job B 


\section{TABLES}

Table 1: Sample Descriptive Statistics

\begin{tabular}{|c|c|c|c|c|}
\hline & Mean & Std. Dev. & Minimum & Maximum \\
\hline Female & 0.77 & & & \\
\hline Hispanic & 0.08 & & & \\
\hline White & 0.84 & & & \\
\hline Black & 0.08 & & & \\
\hline Asian & 0.03 & & & \\
\hline Age & 44.08 & 10.48 & 24 & 81 \\
\hline Total Experience & 15.66 & 8.38 & 2 & 52 \\
\hline Beginning Teachers ${ }^{\text {a }}$ & 0.09 & & & \\
\hline Experience in State & 14.65 & 8.13 & 0 & 52 \\
\hline Salary & 63,406 & 22,447 & 0 & 157,000 \\
\hline Elementary School & 0.44 & & & \\
\hline Secondary School & 0.56 & & & \\
\hline Numerical Ability Score & 4.48 & 1.76 & 0 & 8 \\
\hline Cognitive Reflection Test Score & 1.76 & 1.52 & 0 & 5 \\
\hline Conscientiousness & 4.13 & 0.55 & 2 & 5 \\
\hline \multicolumn{5}{|c|}{ Financial Literacy Questions Correct } \\
\hline 0 & 0.03 & & & \\
\hline 1 & 0.14 & & & \\
\hline 2 & 0.31 & & & \\
\hline 3 & 0.53 & & & \\
\hline \multicolumn{5}{|l|}{ Risk Tolerance } \\
\hline Potential Cut $<0.10$ & 0.33 & & & \\
\hline $0.10<$ Potential Cut $<0.20$ & 0.33 & & & \\
\hline $0.20<$ Potential Cut $<0.33$ & 0.24 & & & \\
\hline $0.33<$ Potential Cut $<0.50$ & 0.05 & & & \\
\hline $0.50<$ Potential Cut $<0.75$ & 0.03 & & & \\
\hline Potential Cut $>0.75$ & 0.02 & & & \\
\hline
\end{tabular}

${ }^{a}$ Beginning teachers are those with between 0 and 5 years of total experience. 
Table 2: Job Conditions and Values

\begin{tabular}{|c|c|c|c|c|}
\hline $\begin{array}{c}\text { Job } \\
\text { Condition }\end{array}$ & Condition Wording & Potential Values & $\begin{array}{l}\text { Frequency } \\
\text { Value } \\
\text { Appears } \\
\end{array}$ & $\begin{array}{l}\text { Probability of } \\
\text { Choosing Value }\end{array}$ \\
\hline \multirow{3}{*}{$\begin{array}{l}\text { Retirement } \\
\text { Plan Type } \\
(5,727)\end{array}$} & \multirow{3}{*}{$\begin{array}{l}\text { The retirement plan } \\
\text { bases benefits on } \\
\text { [value]. }\end{array}$} & $\begin{array}{l}\text { a formula involving a person's age, years of service, } \\
\text { and salary }\end{array}$ & baseline & $29 \%$ \\
\hline & & $\begin{array}{l}\text { how much money has accumulated in a person's } \\
\text { individual account from employee contributions, } \\
\text { employer contributions, and investment returns }\end{array}$ & 2,857 & $72 \%$ \\
\hline & & $\begin{array}{l}\text { employee contributions, employer contributions, and } \\
\text { investment returns with a minimum guarantee }\end{array}$ & 2,870 & $70 \%$ \\
\hline \multirow{9}{*}{$\begin{array}{l}\text { Replacement } \\
\text { Rate } \\
(5,817)\end{array}$} & \multirow{9}{*}{$\begin{array}{l}\text { A teacher who works a } \\
\text { full career in the same } \\
\text { retirement system earns } \\
\text { retirement benefits that } \\
\text { would provide a } \\
\text { monthly check } \\
\text { equivalent to [X] } \\
\text { percent of their end-of- } \\
\text { career salary. }\end{array}$} & 60 & 775 & $64 \%$ \\
\hline & & 62 & 744 & $64 \%$ \\
\hline & & 65 & 755 & $71 \%$ \\
\hline & & 67 & 765 & $73 \%$ \\
\hline & & 70 & baseline & $26 \%$ \\
\hline & & 73 & 658 & $73 \%$ \\
\hline & & 75 & 668 & $78 \%$ \\
\hline & & 78 & 691 & $85 \%$ \\
\hline & & 80 & 761 & $83 \%$ \\
\hline \multirow{5}{*}{$\begin{array}{l}\text { Retirement } \\
\text { Age } \\
(5,743)\end{array}$} & \multirow{5}{*}{$\begin{array}{l}\text { A teacher who works a } \\
\text { full career in the same } \\
\text { retirement system is } \\
\text { eligible to receive } \\
\text { benefits at age }[\mathbf{X}] \text {. }\end{array}$} & 55 & 989 & $78 \%$ \\
\hline & & 57 & 934 & $73 \%$ \\
\hline & & 60 & baseline & $33 \%$ \\
\hline & & 63 & 963 & $72 \%$ \\
\hline & & 65 & 1,002 & $65 \%$ \\
\hline
\end{tabular}




\begin{tabular}{|c|c|c|c|c|}
\hline $\begin{array}{c}\text { Job } \\
\text { Condition }\end{array}$ & Condition Wording & Potential Values & $\begin{array}{c}\text { Frequency } \\
\text { Value } \\
\text { Appears }\end{array}$ & $\begin{array}{l}\text { Probability of } \\
\text { Choosing Value }\end{array}$ \\
\hline & & 67 & 955 & $59 \%$ \\
\hline & & 69 & 900 & $52 \%$ \\
\hline \multirow{5}{*}{$\begin{array}{l}\text { Salary } \\
\text { Growth } \\
(5,809)\end{array}$} & \multirow{5}{*}{$\begin{array}{l}\text { Salary grows by }[\mathbf{X}] \\
\text { percent annually. }\end{array}$} & 2 & 1,458 & $62 \%$ \\
\hline & & 3.5 & 1,450 & $66 \%$ \\
\hline & & 5 & baseline & $26 \%$ \\
\hline & & 6.5 & 1,433 & $82 \%$ \\
\hline & & 8 & 1,467 & $85 \%$ \\
\hline \multirow{3}{*}{$\begin{array}{l}\text { Class Size } \\
(5,917)\end{array}$} & \multirow{3}{*}{$\begin{array}{l}\text { Teachers have class } \\
\text { sizes of approximately } \\
\text { [X] students. }\end{array}$} & -3 & 2,912 & $65 \%$ \\
\hline & & 0 & baseline & $28 \%$ \\
\hline & & +3 & 3,005 & $78 \%$ \\
\hline \multirow{3}{*}{$\begin{array}{l}\text { Health } \\
\text { Insurance } \\
(5,885)\end{array}$} & \multirow{3}{*}{$\begin{array}{l}\text { The health insurance } \\
\text { plan would cover [X] } \\
\text { percent of healthcare } \\
\text { costs for the average } \\
\text { person and provide [Y]. }\end{array}$} & $X=60, Y=$ catastrophic coverage & 2,947 & $62 \%$ \\
\hline & & $\mathrm{X}=80, \mathrm{Y}=$ catastrophic coverage & baseline & $28 \%$ \\
\hline & & $\mathrm{X}=80, \mathrm{Y}=$ catastrophic coverage, dental, and optical & 2,938 & $82 \%$ \\
\hline \multirow{2}{*}{$\begin{array}{l}\text { Social } \\
\text { Security } \\
(5,980)\end{array}$} & \multirow{2}{*}{$\begin{array}{l}\text { Teachers [value] Social } \\
\text { Security. }\end{array}$} & contribute to and earn benefits in & baseline & $38 \%$ \\
\hline & & do not contribute to or earn benefits in & 5,980 & $62 \%$ \\
\hline
\end{tabular}

Notes: Bolded text in the condition wording column is also bolded in the survey to emphasize key elements. 
Table 3: Willingness-to-Pay for Different Retirement Plan Types

\begin{tabular}{rlllc}
\hline & WTP & WTP & WTP & WTP \\
& $(1)$ & $(2)$ & $(3)$ & $(4)$ \\
\hline DC rather than FAS & $-0.034^{* * *}$ & $-0.028^{* * *}$ & $-0.027 * * *$ & $-0.027 * * *$ \\
& $(0.005)$ & $(0.005)$ & $(0.005)$ & $(0.005)$ \\
CB rather than FAS & $-0.027 * * *$ & $-0.021 * * *$ & $-0.019 * * *$ & $-0.019 * * *$ \\
& $(0.005)$ & $(0.005)$ & $(0.005)$ & $(0.005)$ \\
Question FE & & & & \\
State FE & & $\mathrm{X}$ & $\mathrm{X}$ & $\mathrm{X}$ \\
$\mathrm{N}$ & 40,878 & 40,878 & 40,878 & 40,878 \\
\hline
\end{tabular}

Notes: Willingness-to-pay estimates from equation (4) based on results from logistic regression of the model in equation (2). Models include all job conditions. Probability weights included. Standard errors calculated using delta method with clustering by individual in parenthesis; $* * *$ $\mathrm{p}<0.01,{ }^{* *} \mathrm{p}<0.05, * \mathrm{p}<0.1$. 
Table 4: Willingness-to-Pay for Different Retirement Plan Types Mediated by Experience

\begin{tabular}{lclc}
\hline & $\begin{array}{c}\text { Early-Career } \\
(1)\end{array}$ & $\begin{array}{c}\text { Mid-Career } \\
(2)\end{array}$ & \multicolumn{1}{c}{$\begin{array}{c}\text { Late-Career } \\
(3)\end{array}$} \\
\hline & & & \\
DC rather than FAS & -0.008 & $-0.027^{* * *}$ & $-0.048^{* * * *}$ \\
& $(0.010)$ & $(0.007)$ & $(0.011)$ \\
CB rather than FAS & 0.003 & $-0.020^{* * *}$ & $-0.043^{* * *}$ \\
& $(0.010)$ & $(0.007)$ & $(0.011)$
\end{tabular}

Experience Range Less than $8 \quad$ Between 9 and $21 \quad$ More than 22

Notes: Willingness-to-pay estimates from equation (4) based on results from logistic regression of the model in equation (2). Models include all job conditions and state and question fixed effects. $\mathrm{N}=40,878$. Experience range determined using total experience quartiles: early-career respondents are in the first experience quartile, mid-career respondents are in the second or third experience quartiles, late-career respondents are in the fourth experience quartile. Probability weights included. Standard errors calculated using delta method with clustering by individual in parenthesis; $* * * \mathrm{p}<0.01, * * \mathrm{p}<0.05, * \mathrm{p}<0.1$. 
Table 5: Willingness-to-Pay for Job Conditions and Equivalent Valuations with Willingness-toPay for Retirement Plan Type

\begin{tabular}{|c|c|c|c|}
\hline & $\begin{array}{c}\text { WTP } \\
(1)\end{array}$ & $\begin{array}{l}\text { DC Equivalent } \\
\text { Valuation } \\
\text { (2) }\end{array}$ & $\begin{array}{l}\text { CB Equivalent } \\
\text { Valuation } \\
\text { (3) }\end{array}$ \\
\hline Replacement Rate & $\begin{array}{l}0.016^{* * * *} \\
(0.001)\end{array}$ & 1.688 & 1.188 \\
\hline Retirement Age & $\begin{array}{l}-0.024 * * * \\
(0.001)\end{array}$ & -1.125 & -0.792 \\
\hline Salary Growth & $\begin{array}{l}0.057 * * * \\
(0.002)\end{array}$ & 0.474 & 0.333 \\
\hline Class Size & $\begin{array}{l}-0.005^{* * *} \\
(0.001)\end{array}$ & -5.400 & -3.800 \\
\hline $\begin{array}{l}\text { Health Insurance: } \\
60 \% \text { rather than } 80 \%\end{array}$ & $\begin{array}{l}-0.168 * * * \\
(0.007)\end{array}$ & - & - \\
\hline $\begin{array}{l}\text { Health Insurance: add } \\
\text { in Dental \& Optical }\end{array}$ & $\begin{array}{l}0.106^{* * *} \\
(0.005)\end{array}$ & - & - \\
\hline $\begin{array}{l}\text { Do not Enroll in } \\
\text { Social Security }\end{array}$ & $\begin{array}{l}-0.107 * * * \\
(0.005)\end{array}$ & - & - \\
\hline
\end{tabular}

Notes: Willingness-to-pay estimates in Column 1 from equation (4) based on results from logistic regression of the model in equation (2). Model includes retirement plan type and question and state fixed effects. Estimates of willingness-to-pay for retirement plan type are available in Column 4 of Table 3. Probability weights included. Standard errors calculated using delta method with clustering by individual in parenthesis; ${ }^{* * *} \mathrm{p}<0.01, * * \mathrm{p}<0.05,{ }^{*} \mathrm{p}<0.1$. Column 2 is the required change in the corresponding job condition that would offset the willingness-to-pay estimate for DC plans instead of FAS plans. Column 3 is the required change in the corresponding job condition that would offset the willingness-to-pay estimate for CB plans instead of FAS plans. 
Table 6: Willingness-to-Pay for Retirement Job Conditions mediated by Experience

\begin{tabular}{|c|c|c|c|}
\hline & $\begin{array}{c}\text { WTP } \\
(1) \\
\end{array}$ & $\begin{array}{c}\text { DC Equivalent } \\
\text { Valuation } \\
(2) \\
\end{array}$ & $\begin{array}{c}\text { CB Equivalent } \\
\text { Valuation } \\
\text { (3) }\end{array}$ \\
\hline \multicolumn{4}{|l|}{ Panel A: Replacement Rate } \\
\hline Early-Career & $\begin{array}{l}0.015^{* * * *} \\
(0.001)\end{array}$ & 0.533 & -0.200 \\
\hline Mid-Career & $\begin{array}{l}0.016^{* * * *} \\
(0.001)\end{array}$ & 1.688 & 1.250 \\
\hline Late-Career & $\begin{array}{l}0.017 * * * \\
(0.001)\end{array}$ & 2.824 & 2.529 \\
\hline \multicolumn{4}{|l|}{ Panel B: Retirement Age } \\
\hline Early-Career & $\begin{array}{l}-0.022 * * * \\
(0.001)\end{array}$ & -0.364 & 0.136 \\
\hline Mid-Career & $\begin{array}{l}-0.024 * * * \\
(0.001)\end{array}$ & -1.125 & -0.833 \\
\hline Late-Career & $\begin{array}{l}-0.028^{* * * *} \\
(0.002)\end{array}$ & -1.714 & -1.536 \\
\hline \multicolumn{4}{|l|}{ Panel C: Salary Growth } \\
\hline Early-Career & $\begin{array}{l}0.062 * * * \\
(0.003)\end{array}$ & 0.129 & -0.048 \\
\hline Mid-Career & $\begin{array}{l}0.057 * * * \\
(0.002)\end{array}$ & 0.474 & 0.351 \\
\hline Late-Career & $\begin{array}{l}0.052 * * * \\
(0.003)\end{array}$ & 0.923 & 0.827 \\
\hline \multicolumn{4}{|l|}{ Panel D: Class Size } \\
\hline Early-Career & $\begin{array}{l}-0.007 * * * \\
(0.002)\end{array}$ & -1.143 & 0.429 \\
\hline Mid-Career & $\begin{array}{l}-0.005^{* * *} \\
(0.002)\end{array}$ & -5.400 & -4.000 \\
\hline Late-Career & $\begin{array}{l}-0.004 \\
(0.002)\end{array}$ & -12.000 & -10.750 \\
\hline
\end{tabular}




\section{WTP \\ DC Equivalent Valuation}

(1)
(2)

\section{CB Equivalent Valuation}

(3)

\begin{abstract}
Panel E: Health Insurance - $60 \%$ rather than $80 \%$

$\begin{array}{ll}\text { Early-Career } & -0.142^{* * *} \\ & (0.012) \\ \text { Mid-Career } & -0.172^{* * *} \\ & (0.009) \\ \text { Late-Career } & -0.187 * * * \\ & (0.013)\end{array}$

Panel F: Health Insurance - add in Dental \& Optical

Early-Career

$0.103 * * *$

(0.008)

Mid-Career

$0.110 * * *$

(0.006)

Late-Career

$0.101 * * *$

(0.009)

Panel G: Do Not Enroll in Social Security

$\begin{array}{cl}\text { Early-Career } & -0.109 * * * \\ & (0.009) \\ \text { Mid-Career } & -0.104 * * * \\ & (0.007) \\ \text { Late-Career } & -0.108^{* * *} \\ & (0.010)\end{array}$

Notes: Willingness-to-pay estimates from equation (4) based on results from logistic regression of the model in equation (2). Models include all job characteristics and question and state fixed effects. $\mathrm{N}=40,878$. Low experience teachers have 8 years or fewer; Medium experience teachers have between 9 and 21 years; High experience teachers have 22 years or more. Probability weights included. Standard errors calculated using delta method with clustering by individual in parenthesis; $* * * \mathrm{p}<0.01, * * \mathrm{p}<0.05,{ }^{*} \mathrm{p}<0.1$. Column 2 is the required change in the corresponding job condition that would offset the willingness-to-pay estimate for DC plans instead of FAS plans. Column 3 is the required change in the corresponding job condition that would offset the willingness-to-pay estimate for CB plans instead of FAS plans.
\end{abstract}


Table 7: Willingness-to-Pay for Different Retirement Plan Types with Mediators

\begin{tabular}{cccccccc}
\hline & \multicolumn{3}{c}{ DC rather than FAS } & \multicolumn{3}{c}{ CB rather than FAS } \\
& Low & Medium & High & Low & Medium & High \\
& $(1)$ & $(2)$ & $(3)$ & $(4)$ & $(5)$ & $(6)$ \\
\hline \multirow{2}{*}{ Cognitive Ability } & -0.004 & $-0.029 * * *$ & $-0.046 * * *$ & -0.017 & $-0.015 * *$ & $-0.031 * * *$ \\
& $(0.011)$ & $(0.007)$ & $(0.010)$ & $(0.012)$ & $(0.007)$ & $(0.011)$ \\
& & & & & & \\
Conscientiousness & $-0.021 * *$ & $-0.029 * * *$ & $-0.028 * * *$ & -0.010 & $-0.023 * * *$ & $-0.021 * *$ \\
& $(0.010)$ & $(0.007)$ & $(0.010)$ & $(0.010)$ & $(0.007)$ & $(0.011)$ \\
& & & & & & \\
Financial Literacy & -0.001 & $-0.022 * *$ & $-0.039 * * *$ & 0.001 & -0.008 & $-0.034 * * *$ \\
& $(0.012)$ & $(0.009)$ & $(0.007)$ & $(0.013)$ & $(0.009)$ & $(0.007)$ \\
& & & & & & \\
Risk tolerance & $-0.029 * * *$ & $-0.033^{*} * *$ & $-0.020 * *$ & $-0.019 * *$ & $-0.027 * * *$ & -0.011 \\
& $(0.009)$ & $(0.009)$ & $(0.008)$ & $(0.010)$ & $(0.009)$ & $(0.008)$
\end{tabular}

Notes: Willingness-to-pay estimates from equation (4) based on results from logistic regression of the model in equation (2). Models include all job conditions and state and question fixed effects. $\mathrm{N}=40,878$. Low-cognitive ability and conscientiousness teachers are in the first quartile; Mediumcognitive ability and conscientiousness teachers are in the second and third quartiles Highcognitive ability and conscientiousness teachers are in the fourth quartile. Low-financial literacy teachers answer 0 or 1 of 3 questions correctly; Medium-financial literacy teachers answer 2 of 3 questions correctly; High-financial literacy teachers answer all questions correctly. Low-risk tolerance teachers are unwilling to take the job when the potential pay cut is less than 10 percent; Medium-risk tolerance teachers are willing to take the job when the potential pay cut is between 10 and 20 percent; High-risk tolerance teachers are willing to take the job when the potential pay cut is greater than 20 percent. Probability weights included. Standard errors calculated using delta method with clustering by individual in parenthesis; $* * * \mathrm{p}<0.01, * * \mathrm{p}<0.05, * \mathrm{p}<0.1$. 


\section{Appendix A: Hypothetical Job COMPARison ConstruCtion}

We use a four-step procedure to construct the hypothetical job offers presented to respondents by randomizing salary offers and one non-salary job conditions. We start by randomly generating two salary perturbations from a normal distribution with mean 1 and standard deviation 0.05. These perturbations are multiplied by the respondents' reported salaries to create the salary offers in our hypothetical job scenarios. Next, we randomly choose one of the seven possible nonsalary job conditions where each job condition has the same likelihood of being selected. Then, we randomly pick one value corresponding with the selected job condition to vary from the job condition's baseline value. We then randomly pick whether the baseline job is offered as Job A or Job B and assign the relevant job condition values and salary perturbations. In the final step, salaries are assigned to teachers to prevent strictly dominating job offers. We assume that teachers would always select a job that corresponds with a higher salary and a larger replacement rate, earlier retirement, higher salary growth, smaller class sizes, or additional health insurance. For example, we would always expect respondents to choose the job that offers 8 percent annual salary growth and a $\$ 50,000$ salary instead of the job that offers 5 percent annual salary growth and a $\$ 49,000$ salary. Switching the salary offer forces a meaningful comparison about a respondent's willingness to pay for the extra 3 percentage points of salary growth. We have no prior expectation for one value for retirement plan type or for Social Security eligibility to strictly dominate in the same way that our other job condition values dominate.

Next, we create a table for the job offers and place the salaries in the corresponding job columns. Next, we fill in the baseline job offer column with the set of unvaried baseline job conditions. The randomly selected job condition is filled in next with the randomly chosen condition value. The rows corresponding with the randomly selected job condition and salaries are 
shaded to increase visibility to respondents about how the job offers are different. Key differing text in the randomly selected job condition and the salary are bolded. The rest of the table is filled in with the baseline job offer. Figure 1 is an example of two job offers where both jobs are exactly the same other than the retirement ages and salaries.

When teachers in the sample do not provide their salary information, we use their state average teacher salary rounded to the nearest $\$ 10,000$. State average teacher salaries are also used when respondents' reported salaries are under $\$ 10,000$. If respondents do not indicate which state they teach in, we use the national average teacher salary instead.

If class size is the job condition randomly selected, we either add or subtract 3 students from the state average school level class size rounded to the nearest integer. We consider elementary teachers to be those who teach grade K-6 and secondary teachers to be those who teach grades 7-12. Again, the national average school level class size is imputed if respondents do not indicate which state they teach in. Respondents leaving our question for the grades they teach blank or who indicate they teach elementary and secondary grades are assigned the average values corresponding to secondary schools. We obtain average teacher salaries and average class sizes information from the Digest of Education Statistics (Snyder et al., 2019). ${ }^{1}$

${ }^{1}$ State average class sizes for the District of Columbia, Florida, Hawaii, Maryland, and Rhode Island are not reported due to a failure of reporting standards to be met. See Table 209.30 of the Digest of Education Statistics for additional information (Snyder et al., 2019). 